\title{
IMPLEMENTASI MANAJEMEN PERUBAHAN PADA BANK PEMBANGUNAN DAERAH DALAM TRANSFORMASI MENUJU REGIONAL CHAMPION BANK
}

\author{
Juhadi \\ Perbankan Syariah, STEI Al-Amar Subang \\ Email : jahfalnet@gmail.com
}

\begin{abstract}
Abstrak
Dalam meningkatkan kualitas sebuah organisasi dibutuhkan sebuah perubahan pada tata kelola manajemen. Bank Pembangunan Daerah dalam proses transformasi menjadi Regional Champion Bank melakukan penerapan manajemen perubahan. Penelitian ini dilakukan dengan mengambil sampel cabang Bank Pembangunan Daerah Subang. Metode yang digunakan dalam penelitian ini adalah metode deskriptif kualitatif. Hasil penelitian menunjukan bahwa strategi penerapan manajemen perubahan Bank Pembangunan Daerah dalam proses transformasi menjadi regional champion bank diantaranya adalah memperkuat leadership di segmen wholesale dengan melakukan pendalaman relationship dengan nasabah, Bank Pembangunan Daerah ingin menjadi Bank Utama pilihan nasabah SME, melalui penetrasi dan akuisisi nasabah yang difokuskan pada sektor-sektor potensial dan Bank Pembangunan Daerah fokus pada membangun kepemimpinan melalui penawaran produk consumer yang lengkap dan berdaya saing, memiliki inovasi untuk memperkuat dominasi di retail payment. Rencana manajemen perubahan yang dilakukan di cabang Bank Pembangunan Daerah Subang, yaitu restrukturisasi organisasi berbasis kinerja, penataan ulang sistem penilaian berbasis kinerja, membangun program pengembangan leadership dan talent serta pengembangan dan pengelolaan program aliansi.
\end{abstract}

Kata Kunci: Manajemen Perubahan, Bank

\section{PENDAhuluan}

Perubahan zaman memasuki hyper competitive atau persaingan yang sangat ketat di segala bidang. Hal ini merupakan dampak dari perdagangan bebas, arus globalisasi yang tidak mungkin diredam, dan perkembangan informasi teknologi yang kian pesat. Semua perubahan ini merupakan akumulasi dari sebuah zaman yang memasuki era revolusi industri 4.0. Berdasar pada sejarahnya bahwa saat akhir abad 20 dibicarakan mengenai era global dimana dirasakan seperti tidak ada lagi batas-batas suatu negara. Demikian bebasnya barang,jasa dan informasi menembus masuk dan keluar dari suatu negara dan tidak terbendung lagi. Menurut (Arifudin, 2020) perkembangan dalam dunia usaha di Indonesia saat ini yang semakin cepat dan pesat berakibat juga pada perubahan budaya. Sehingga organisasi dituntut untuk mempunyai budaya yang membedakan dengan organisasi lain yang sejenis. Perubahan sudah merupakan fenomena global yang tidak bisa dibendung.

Bergulirnya era Asean Economic Community (MEA) yang akan dihadapi Indonesia tahun 2020, sebagai konsekuensi kesepakatan ini membuka lebar pasar ekonomi di kawasan regional Asean,jika ingin terlibat dan diperhitungkan maka Indonesia harus berbenah. Semua sektor industri harus dilengkapi kemampuan untuk bisa bersaing dengan negara Asean lainnya. Melalui MEA aliran masuk barang, jasa dan tenaga kerja terlatih serta aliran investasi akan lebih bebas. Dalam penerapannya. ME akan menerapkan 12 sektor prioritas yang disebut free flow of skilled labor (arus bebas tenaga kerja terampil). Ke 12 sektor terampil itu adalah untuk perawatan kesehatan,turisme,jasa logistik,jasa angkutan udara, produk berbasis agro,barang-barang elektronik, perikanan, produk berbasis karet, tekstil dan 
pakaian,otomotif,dan produk berbasis kayu. Kerangka kerja atau pilar MEA terdiri dari empat uraian yaitu :

a. Sebagai pasar tunggal dan basis produksi internasional dengan elemen aliran bebas barang, jasa, investasi, tenaga kerja terampil dan aliran modal yang lebih bebas

b. Sebagai kawasan dengan daya saing ekonomi yang tinggi, dengan elemen peraturan kompetisi, perlindungan konsumen, hak atas kekayaan intelektual, pengembangan infrastruktur, perpajakan dan e commerce

c. Sebagai kawasan dengan perkembangan ekonomi yang merata bagi negara negara yang termasuk CLMV (Kamboja, Laos, Myanmar, Vietnam) yang termuat dalam Initiative for ASEAN Integration

d. Sebagai kawasan yang terintegrasi secara penuh dengan perekonomian global.(Cermati.com. diakses.2 Februari 2020)

Melalui MEA ini memiliki tujuan adalah dengan adanya aliran masuk barang, jasa,dan tenaga kerja terlatih serta aliran investasi yang lebih bebas.

Tabel 1.1

Peringkat Kapitalisasi pasar dan asset bank di Asean

\begin{tabular}{|c|c|c|c|c|}
\hline $\begin{array}{c}\text { Kepitalisei } \\
\text { Paser } \\
\text { Peringly }\end{array}$ & NarneBartk & Negra & NarraBartz & Negara \\
\hline 1 & DBS & Singopura & DES & Singepura \\
\hline 2 & $\alpha C B C$ & Singopura & $\alpha O B$ & Singepora \\
\hline 3 & MEyberit: & MElaysia & $\mathrm{UCB}$ & Singepura \\
\hline 4 & $\mathrm{UCB}$ & Singopura & MEgbert: & MElaysia \\
\hline 5 & Pubtic Bent: & MElaysia & GMB & Malaysia \\
\hline 6 & $\mathrm{BCA}$ & Inctresia & Public Bertr & Malaysia \\
\hline 7 & GMB & MElaysia & Benglat-Berts & Theilend \\
\hline 8 & MEnderi & Inthresia & Menderi & Indonesia \\
\hline 9 & BFI & Incteresia & BRI & Indonesia \\
\hline 10 & SianCormercial & Theil and & $\mathrm{BCA}$ & Indonesia \\
\hline
\end{tabular}

Sumber : Dwi Ayu dalam Bloomberg INDEF (2016)

Dari tabel diatas terlihat bahwa peta kekuatan perbankan di Asean, Singapura lebih unggul dalam, jumlah asset maupun tingkat kesehatannya. Perbankan Thailand menunjukan kemampuan yang baik yaitu dengan jumlah bank yang tidak banyak tetapi terdapat bank yang go internasional seperti Bangkok Bank. Kondisi perbankan di negara Singapura dan Thailand, bila dibandingkan dengan bank yang ada di Indonesia maka Bank diIndonesia belum bisa bersaing secara maksimal. Bank Mandiri, BCA dan BRI termasuk kedalam 10 bank dengan kapitalisasi pasar dan aset terbesar di Asean. Namun hal ini jika dilihat dari kapitalisasi pasar dan assetnya, maka perbankan di Indonesia masih terbilang rendah bila dibandingkan dengan perbankan yang ada di Asean. Contohnya Bank Mandiri yang menduduki posisi 8 di Asean sedangkan yang menduduki posisi pertama di Bank Asal negara Singapura

Transformasi harus dilakukan oleh Bank Pembangunan Daerah mengingat setelah merger Bank Pembangunan Daerah memiliki corporate culture yang lemah. Budaya kerja tidak di implementasikan secara konsisten. Maka daripada itu diperlukan revitalisasi corporate culture. Budaya perusahaan yang kuat dan diimplementasikan secara konsisten sebagai landasan keberhasilan transformasi di Bank Pembangunan Daerah. 
Program transformasi di Bank Pembangunan Daerah dilakukan selama 3 fase yaitu :

Tabel 1.2

Tahapan Transformasi PT Bank Pembangunan Daerah (Persero) Tbk

\begin{tabular}{|l|l|l|}
\hline TAHAP I & Back On Track & $\begin{array}{l}\text { Fokus untuk merekon struksi ulang } \\
\text { fondasi Bank Pembangunan Daerah } \\
\text { untuk pertumbuhan di masa depan }\end{array}$ \\
\hline TAHAP II & Outperform the Market & $\begin{array}{l}\text { Fokus pada ekspansi bisnis untuk } \\
\text { menjamin pertumbuhan yang } \\
\text { signifikan di berbaga segmen dan } \\
\text { mencapai level profit yang mampu } \\
\text { melampaui target rata-rata pasar }\end{array}$ \\
\hline TAHAP III & Shaping the End Game & $\begin{array}{l}\text { Bank Pembangunan Daerah } \\
\text { menargetkan diri untuk menjadi bank } \\
\text { regional terdepan melalui konsolidasi } \\
\text { dari bisnis jasa keuangan dan lebih } \\
\text { mengutamakan peluang strategi } \\
\text { pertumbuhan non organik,termasuk } \\
\text { memperkuat kinerja anak perusahaan } \\
\text { dan akusisi bank atau perusahaan } \\
\text { keuangan lainnya yang dapat } \\
\text { memberikan nilai tambah bagi Bank } \\
\text { Pembangunan Daerah }\end{array}$ \\
\hline
\end{tabular}

Fase-fase ini dilakukan untuk mencapai tujuan Bank Pembangunan Daerah menjadi Regional Champion Bank. Hal ini bukan pekerjaan mudah bagi Bank Pembangunan Daerah untuk mewujudkan visinya mejadi regional champion bank sebab langkah Bank Pembangunan Daerah untuk go internasional di kawasan Asia Tenggara pada khususnya baru akan berjalan mulus ketika Bank Pembangunan Daerah mampu mengimbangi bank bank besar ASEAN lainnya seperti bank besar dari Malaysia yaitu Maybank dan CIMB atau bank besar dari Singapore yaitu DBS, OCBC dan UOB

Berdasar data bahwa awal september tahun 2014, pemerintah menerbitkan Inpres no. 6/2014 tentang peningkatan daya saing menghadapi Masyarakat Ekonomi Asean, pemerintah Indonesia sudah menyiapkan pengembangan sektor industri agar bisa bersaing di pasar bebas Asean. Salah satu sektor nya adalah sektor perbankan yang masuk kedalam 10 pengembangan industri yang harus diantar ke gerbang pasar bebas dengan semua keunggulannya. Industri perbankan tidak hanya menjadi tuan rumah di negara sendiri tetapi juga memperlebar ekspansinya ke negara Asean lainnya. Hambatan yang terjadi dalam transformasi dunia perbankan yakni dalam setiap upaya merger selalu dihadapkan pada maslah perbedaan corporate culture dan keengganan pemilik bank menjadi orang nomor dua. Sehingga para pengambil kebijakan sudah sewajarnya mendorong kalangan perbankan nasional menyiapkan SDM yang handal. 
Oleh karena itu untuk melihat sejauhmana perubahan yang dilakukan oleh Bank Pembangunan Daerah, maka penulis tertarik untuk melakukan penelitian dengan judul "implementasi manajemen perubahan pada Bank Pembangunan Daerah dalam proses transformasi menjadi Regional Champion Bank". (Studi kasus di cabang Bank Pembangunan Daerah Subang).

\section{KAJIAN PUSTAKA}

Menurut (Tim Creacev, 2011) Director of Research and Development Prosci Research mengemukakan bahwa Manajemen perubahan adalah suatu proses, alat dan teknik untuk mengelola orang-orang untuk berubah dalam rangka mencapai tujuan bisnis yang telah ditentukan. Tujuan utama dari perubahan itu adalah untuk meningkatkan kinerja organisasi dengan cara merubah bagaimana cara mengerjakan pekerjaan yang lebih baik. Pendapat lain menurut (Partridge, 2007) menyatakan bahwa manajemen perubahan dapat dinyatakan sebagai pengelolaan transisi dari situasi lama ke situasi baru. Hal ini dapat dilakukan dengan melakukan pencairan (unfreezing), pada situasi yang lama dan pemantapan bentuk (refreezing) ke dalam siatuasi baru, sehingga menjadi suatu situasi yang mapan.

Berdasarkan beberapa definisi tersebut, dapat dikemukakan di sini bahwa, manajemen perubahan adalah suatu pendekatan, alat, teknik dan proses pengelolaan sumber daya untuk membawa organisasi pada keadaan sekarang menuju keadaan baru yang diinginkan, agar kinerja organisasi menjadi lebih baik. Dalam organisasi, perubahan itu meliputi individu, tim, organisasi, struktur, proses, pola fikir dan budaya kerja

Pengelolaan yang baik, menggunakan fungsi-fungsi manajemen. Menurut (Terry, 2009), fungsi manajemen adalah Planning (perencanaan), Organizing (pengorganisasian), Actuating (pelaksanaan) dan Controlling (pengendalian). Pendapat lain Menurut (Kotler, Philip, 2012) bahwa fungsi manajemen adalah: Planning (perencanaan) Organizing (pengorganisasian), Leading (pemimpinan) dan Controlling (pengendalian)

Menurut (Arifudin, 2019) bahwa banyak sekali jenis atau macam perusahaan yang mempekerjakan manusia dalam proses produksinya, karena faktor manusia adalah salah satu dari kunci keberhasilan perusahaan dalam mencapai tujuan yang terkenal dengan istilah 7M yaitu Man (manusia), Money (uang), Materials (bahan), Machines (peralatan kerja), Methods (metode kerja), Market (pasar) dan Minute (waktu). Kriteria pencapai tujuan adalah efektif dan efisien. Bila proses pengelolaan yang menggunakan fungsi manajemen dari (Robinns dan Coulter,2008) diinteraksikan dengan sumber daya yang dikelola, maka manajemen perubahan dapat digambarkan seperti gambar 1 berikut:

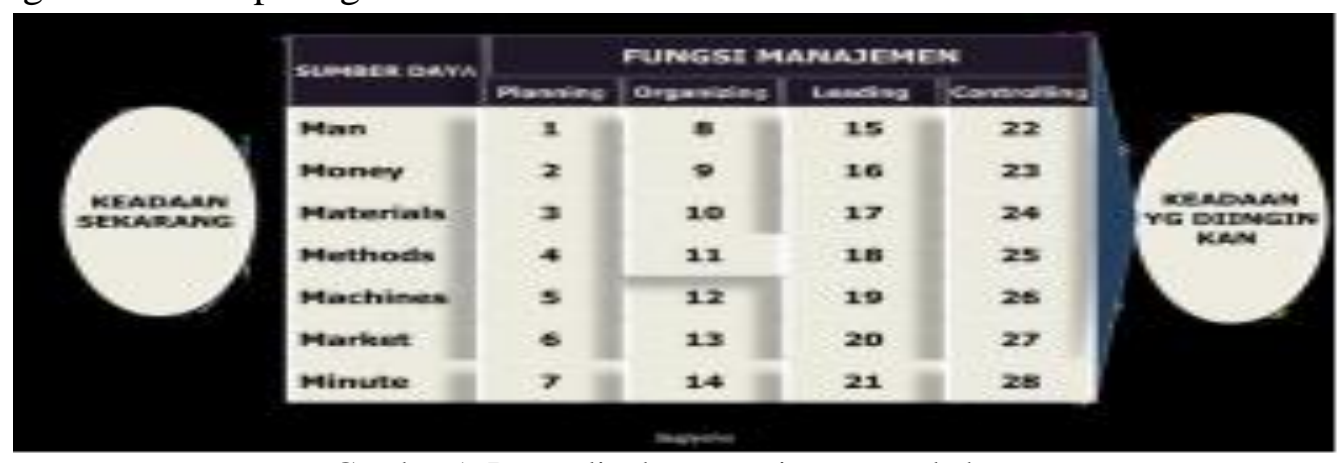

Gambar 1. Ruang lingkup manajemen perubahan 
Berdasarkan gambar 1 tersebut, dapat dikemukakan bahwa, sebelum proses pengelolaan sumber daya dilakukan, maka terlebih dulu diketahui keadaan sekarang (existing condition) secara lengkap, akurat dan obyektif. Setelah kondisi sekarang ditetapkan, maka selanjutnya ditentukan arah kondisi yang diinginkan juga ditetapkan. Dengan mengetahui secara pasti kondisi sekarang dan kondisi yang akan datang, maka kegiatan pengelolaan sumber daya (manajemen) untuk mencapai tujuan perubahan dapat dilakukan.

Manajemen perubahan sering disebut dengan manajemen transisi dan manajemen inovasi. Dikatakan manajemen transisi, karena mengelola keadaan yang bersifat transisi dari kondisi lama menuju kondisi baru. Dikatakan manajemen inovasi, karena tujuan dari perubahan adalah untuk pembaruan, dari yang lama ke yang baru supaya lebih baik

Perbedaan utama antara manajemen perubahan dengan manajemen yang konvensional/biasa adalah terletak adanya faktor-faktor kuat yang menghambat perubahan. Faktor-faktor penghambat tersebut perlu dikelola agar berubah menjadi faktor pendorong perubahan. Karena adanya hambatan, maka kemungkinan perjalanan dalam mencapai tujuan perubahan ditunjukkan pada gambar 2 Berdasarkan gambar 2 tersebut terlihat bahwa, pencapaian perubahan yang efektif ditunjukkan dalam lintasan 1 . Lintasan 1 merupakan garis lurus, garis yang terpendek untuk mencapai visi perubahan. Lintasan 2, 3, dan 4, adalah suatu lintasan untuk mencapai visi yang tidak efisien, karena harus berbelok-belok baru mencapai tujuan. Lintasan 5,8 adalah suatu contoh manajemen perubahan yang tidak mencapai sasaran.

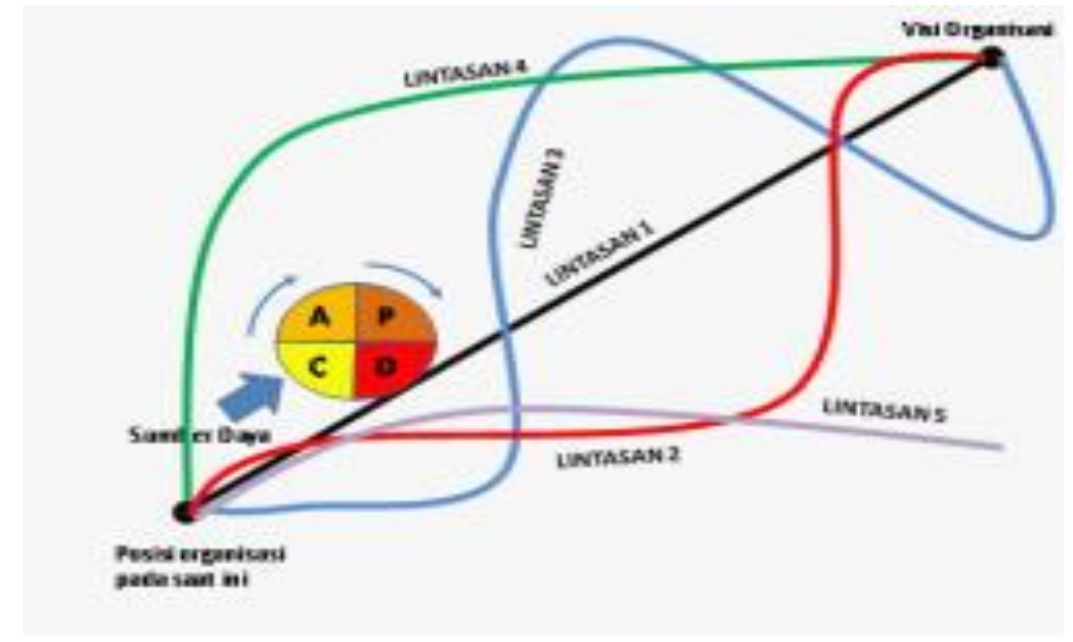

Gambar 2 Berbagai kemungkinan dalam mencapai visi perubahan

Perubahan adalah respon terencana atau tak terencana terhadap tekanan-tekanan dan desakandesakan yang ada. Manajemen Perubahan adalah upaya yang dilakukan untuk mengelola akibat-akibat yang ditimbulkan karena terjadinya perubahan dalam organisasi. Perubahan mempunyai manfaat bagi kelangsungan hidup suatu organisasi, tanpa adanya perubahan maka dapat dipastikan bahwa usia organisasi tidak akan bertahan lama. Perubahan dapat terjadi karena sebab-sebab yang berasal dari dalam maupun dari luar organisasi tersebut. Perubahan bertujuan agar organisasi tidak menjadi statis melainkan tetap dinamis dalam menghadapi perkembangan jaman, kemajuan teknologi dan dibidang pelayanan masyarakat adalah peningkatan kesadaran masyarakat akan pelayanan yang berkualitas. 


\section{METODE PENELITIAN}

Metode yang digunakan dalam penelitian ini adalah metode deskriptif kualitatif. Dalam penelitian terkait implementasi manajemen perubahan pada Bank Pembangunan Daerah dalam proses transformasi menjadi regional champion Bank, dilakukan berbagai persiapan sebelum penelitian yakni mengidentifikasi masalah/mencari permasalahan, merumuskan masalah, mengadakan studi pendahuluan, dan menentukan sampel penelitian. Fokus dalam penelitian terkait implementasi manajemen perubahan pada Bank Pembangunan Daerah dalam proses transformasi menjadi regional champion Bank ini memiliki dua tujuan yang penting, yakni menetapkan fokus untuk membatasi studi, dalam hal ini membatasi bidang inkuiri, misalnya, membatasi diri pada penggunaan teori yang sesuai dengan masalah yang diteliti, sedang teori yang tidak sesuai sedapat mungkin dihindari penggunaannya, dan menetapan focus penelitian berfungsi untuk memenuhi kriteria inkluisi-inkluisi seperti perolehan data yang baru dilapangan. Untuk memperoleh data dan informasi yang akurat, maka diperlukan teknik pengumpulan data yang sesuai dengan metode penelitian kualitatif. Teknik pengumpulan data tersebut terdiri dari wawancara dan dokumentasi.

Menurut (Moleong, 2007) bahwa fokus penelitian membantu peneliti dalam mengetahui dengan pasti data yang perlu dikumpulkan dan data yang tidak perlu dalam proses pengumpulan data. Sehingga, dengan langkah menetapkan fokus secara jelas dan valid, seorang peneliti dapat membuat keputusan yang tepat tentang data mana yang akan di kumpulkan dan mana yang tidak diperlukan.

Masalah yang terjadi dan fokus penelitian sangat terkait, oleh karena itu permasalahan penelitian dijadikan sebagai acuan di dalam fokus, walaupun fokus dapat berubah dan berkembang secara bebas berdasar pada fenomena-fenomena di lapangan sesuai dengan perkembangan permasalahan penelitian yang ditemukan dilapangan. Tempat penelitian adalah tempat peneliti dapat menangkap keadaan yang sebenarnya dari objek yang akan diteliti. Adapun lokasi penelitian adalah cabang Bank Pembangunan Daerah yang terletak di Kantor Cabang Kabupaten Subang, penetapan lokasi penelitian ini dikarenakan Cabang Bank Pembangunan Daerah ini memiliki masalah yang kompleks untuk diteliti.

\section{HASIL DAN PEMBAHASAN}

Hasil penelitian terkait implementasi manajemen perubahan pada Bank Pembangunan Daerah dalam proses transformasi menjadi regional champion Bank dilihat dari hasil observasi, wawancara dan dokumentasi. Berdasarkan hasil triangulasi yakni kebenaran data dengan membandingkan data dan informasi data dari sumber lain. Data yang diperoleh dari peneliti dari hasil wawancara, obeservasi dan studi dokumentasi dicek kebenarannya melalui narasumber yang berkaitan dengan penelitian ini maka secara valid menghasilkan berbagai data-data terkait penelitian implementasi manajemen perubahan pada Bank Pembangunan Daerah dalam proses transformasi menjadi regional champion Bank yakni sebagai berikut :

a. Strategi penerapan manajemen perubahan dalam proses transformasi menjadi Regional Champion Bank

1. Memperkuat leadership di segmen wholesale dengan melakukan pendalaman relationship dengan nasabah

2. Bank Pembangunan Daerah ingin menjadi penantang terkuat di pasar 
3. Bank Pembangunan Daerah ingin menjadi Bank Utama pilihan nasabah SME, melalui penetrasi dan akuisisi nasabah yang difokuskan pada sektor-sektor potensial

4. Bank Pembangunan Daerah fokus pada membangun kepemimpinan melalui penawaran produk consumer yang lengkap dan berdaya saing, memiliki inovasi untuk memperkuat dominasi di retail payment.

5. Mengintegrasikan bisnis di semua segmen yang ada di Bank Pembangunan Daerah, termasuk dengan Perusahaan Anak

b. Rencana manajemen perubahan yang dilakukan di cabang Bank Pembangunan Daerah

1. Restrukturisasi organisasi berbasis kinerja

2. Penataan ulang sistem penilaian berbasis kinerja

3. Membangun program pengembangan leadership dan talent

4. Pengembangan dan pengelolaan program aliansi.

c. Pencapaian manajemen perubahan di Bank Pembangunan Daerah dalam proses transformasi menjadi Regional Champion Bank

1. Fokus pada penanganan kredit macet

2. Memperkuat risk manajemen system

3. Kinerja keuangan yang sustainable

4. Delivery channel yang beragam dengan pelayanan prima

5. Legenda pelayanan prima untuk front liniers selama 9 tahun berturut-turut

d. Hambatan/kendala-kendala dalam pelaksanaan penerapan manajemen perubahan di Bank Pembangunan Daerah

1. Masih adanya sikap silo, terkotak-kotak dan apatis

2. Business process dan operasional masih belum mencapai tingkat efisiensi dan kehandalan yang kompetitif

3. Platform IT yang belum sepenuhnya reliable untuk mendukung pertumbuhan bisnis yang agresif

4. Corporate culture yang lemah

5. Budaya kerja tidak dimplementasikan secara konsisten

6. Masalah sebelumnya belum terpecahkan

7. Lambatnya sosialisasi kebijakan baru dari kantor pusat ke kantor-kantor cabang di wilayah.

8. Kompetensi, engagement SDM efek teknologi informasivitas organisasi belum maksimal

9. Perubahan organisasi di Cabang belum sepenuhnya diikuti oleh perubahan sales/service model pengelolaan nasabah

\section{KESIMPULAN}

Berdasarkan hasil penelitian terkait implementasi manajemen perubahan pada Bank Pembangunan Daerah dalam proses transformasi menjadi regional champion Bank Studi Kasus di Kantor Cabang Kabupaten Subang bahwa dapat disimpulkan yakni sebagai berikut :

1) Ada hubungan yang sangat signifikan dan positif antara persepsi gaya kepemimpinan transformasional dan kepuasan kerja

2) Menintegrasikan segmen bisnis yang bervariasi 
3) Focus penanganan kredit macet yang terjadi

4) Pengembangan sumber daya manusi (SDM) dalam digitalisasi layanan.

Adapun saran berdasarkan hasil penelitian diatas terkait implementasi manajemen perubahan pada Bank Pembangunan Daerah dalam proses transformasi menjadi regional champion Bank Studi Kasus di Kantor Cabang Kabupaten Subang yakni sebagai berikut :

1) Memperkuat kepemimpinan dalam manajemen perubahan

2) Melatih karyawannya untuk siap menerima perubahan (ready to change) dan mampu menjalankan perubahan (capacity to change)

3) Alangkah baiknya apabila semua karyawan dilibatkan

4) Perlu adanya penghargaan kepada mereka yang mendukung perubahan, seperti menghargai komitmen waktu, termasuk kerja lembur, dan usaha yang telah dilakukan dalam menyusun proses kerja baru

5) Penyesuaian struktur organisasi untuk memastikan kolaborasi di seluruh jajaran organisasi

6) Merangkul seluruh jajaran organisasi tanpa membedakan gender,usia, backround, unit kerja dll namun tetap berorientasi kepada kinerja

\section{REFERENSI}

Arifudin, O. (2019). Pengaruh Kompensasi Terhadap Kinerja Karyawan Di PT. GLOBAL (PT.GM). Jurnal Ilmiah MEA (Manajemen, Ekonomi, \& Akuntansi), 3(2), 184-190.

Arifudin, O. (2020). Analisis Budaya Organisasi Dan Komitmen Organisasi Karyawan Bank Swasta Nasional Di Kota Bandung. Jurnal Ilmiah MEA (Manajemen, Ekonomi, Dan Akuntansi), 4(2), 73-87.

Kotler, Philip, dan G. A. (2012). Prinsip-prinsip Pemasaran. Edisi 13. Jakarta : Erlangga.

Moleong. (2007). Metodologi Penelitian Kualitatif. Bandung: PT. Remaja Rosdakarya.

Partridge. (2007). Managing Change (Learning Made Simple). Nee York, Lewis Publisher.

Terry. (2008). Prinsip-prinsip Manajemen. Bandung : PT. Bumi Aksara.

Tim Creacev. (2011). Beyon Change Management Advenced Strategies for Today's Transformational Leader. San Fransisco:Jossey-Bass. 